the specimen before publication of the cemetery report; and Jean Brown of the Photography Department, University of Bradford, for reproducing the photograph.

1 Trotter M. Estimation of stature from intact long limb bones. In: Stewart TD, ed. Personal identification in mass disasters. Washington: National Museum of Natural History, 1970:71-83. 2 Ortner DJ, Putschar WGJ. Identification of pathological conditions in human skeletal remains.

Washington: Smithsonian Institution Press, 1981.

Calvin Wells Laboratory, School of Archaeological Sciences, University of Bradford, Bradford BD7 1DP

CHARLOTTE A ROBERTS, .MA, SRN, research assistant

\section{Cross reaction to a Christmas tree}

I report on a patient who is resigned to having an artificial Christmas tree this year. Her experience with a real one last year gave her more than just the needle.

\section{Case report}

A 26 year old woman was referred during Advent 1986, having woken with an itchy rash on the face and dorsa of the hands two days previously. The rash had initially been attributed either to her soap powder or to recent use of a household spray. On examination she had acute eczema of the face and hands, extending slightly up the forearms. She recalled no previous dermatological problems other than that she had been allergic to Elastoplast as a child.

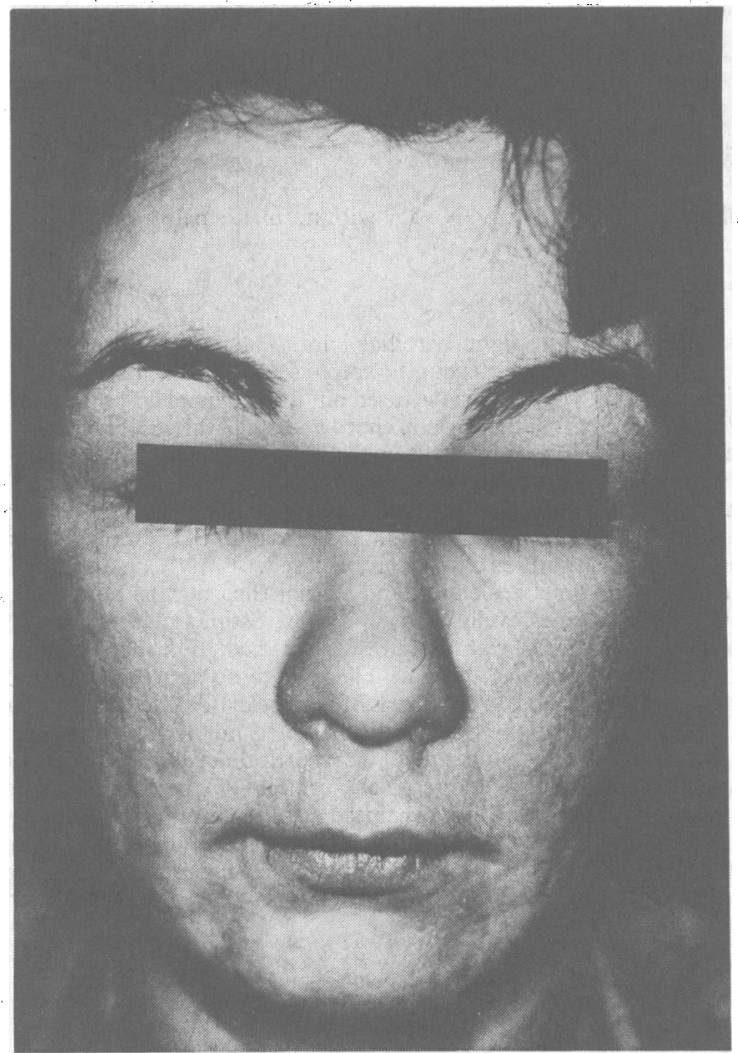

Facial appearance at presentation.

Further inquiry disclosed that four days previously she and her husband had selected a Christmas tree. She remarked that the chosen specimen was the strongest smelling Christmas tree that she had ever come across, and on the journey home she was in close proximity to it in the back of their Ford Fiesta. While decorating the tree that night she came into contact not only with the bark, branches, and needles but also with resin that was exuding freely from the trunk. Her rash appeared about 36 hours later.

She was treated with a course of prednisolone (reducing from $30 \mathrm{mg}$ daily to zero over six days) and $1 \%$ hydrocortisone cream, and her eczema had resolved completely when she was seen one week later.

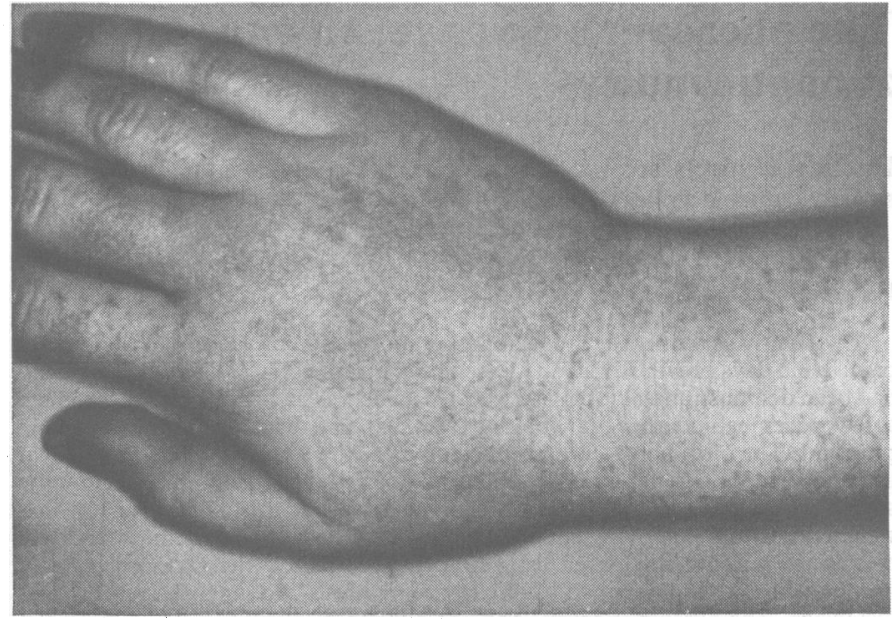

Appearance of hand at presentation.

A diagnosis of allergy to Christmas trees was suggested, and she was patch tested with a battery of allergens, including the standard battery of the International Contact Dermatitis Research Group, her household spray, and bark and needles from the offending Christmas tree. The diagnosis was confirmed by strongly positive reactions to colophony (rosin), bark, and needles at 48 hours. (The bark or needles were not expected to provoke an irritant reaction, and no control tests were performed.) The botanical identity of the tree remained a mystery because it had been disposed of quite promptly.

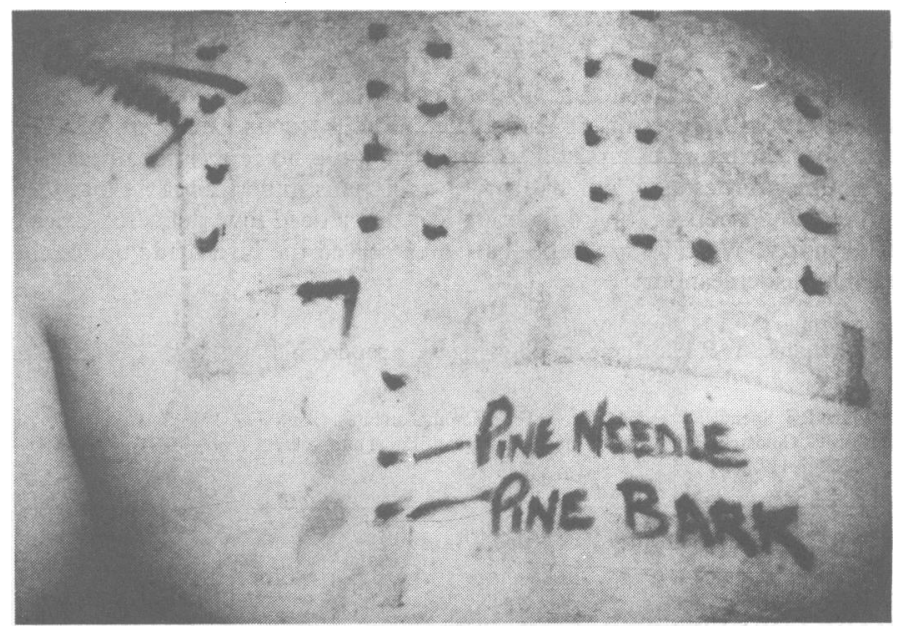

Positive reactions to patch tests of colophony, pine needles, and bark.

\section{Comment}

The family Pinaceae consists of 250 species in ten genera and includes pine, fir, and spruce. ${ }^{1}$ Occupational contact dermatitis caused by these trees is a recognised problem in, for example, woodcutters, forest workers, carpenters, and florists, who may become sensitised by contact with the wood, sawdust, or lichens living on the bark. The main sensitising substances are terpenes such as $\alpha$-pinene, $\delta$-3-carene, and abietic acid (from abies (Latin), meaning a fir. $)^{1}$

Several constituents of everyday products derived from Pinaceae trees also have the potential to produce contact dermatitis. These include Canada balsam (derived from the fir Abies balsamea), turpentine (obtained from several different species, depending on geographical locality), and colophony. ${ }^{1}$ Colophony (rosin) is derived mainly from Pinus palustris and, though it probably consists of several hundred substances, its main constituents are abietic acid and its isomers or derivatives.

Domestically, colophony is present in varnishes and furniture polish. The commonest cause of allergy, however, is adhesive tape..$^{1-5}$ Though antioxidants and preservatives in the tape may cause contact allergy, positive reactions to patch tests are usually due to colophony or abietic acid derivatives, or both, which are present in the adhesive itself. ${ }^{2.5}$ Cross sensitivity between plasters and trees of the Pinaceae family is recognised by dermatologists (in, for example, two patients who were sensitised by plaster and cross reacted to their Cupressus leylandii hedges) ${ }^{45}$ but probably not by others. 
Our patient gave a clear history of contact sensitivity to Elastoplast. Patch testing confirmed her sensitivity to colophony and the unfortunate cross reaction to her Christmas tree. She declined to consider any of the other 249 species in the Pinaceae family this year and opted for an artificial tree. She was advised not to get too close to other people's trees-and not to get plastered.

I thank Dr C M King for performing patch testing.

1 Mitchell J, Rook A. Botanical dermatology. Vancouver: Greenglass, 1979:514-25.

2 Cronin E, Calnan CD. Allergy to hydroabietic alcohol in adhesive tape. Contact Dermatitis 1978;4:57.

3 Sjöborg S, Fregert S. Allergic contact dermatitis from a colophony derivative in a tape skin closure. Contact Dermatitis 1984;10:114-5.

4 Hindson C, Lawlor F, Downey A. Cross sensitivity between zinc oxide plaster and Cupressus leylandii shrubs. Contact Dermatitis 1982;8:335.

5 Lovell CR, Dannaker CI, White IR. Dermatitis from X Cupressocyparis leylandii and concomitant sensitivity to colophony. Contact Dermatitis 1985;13:344-5.

University Department of Dermatology, Royal Liverpool Hospital, PO Box 127, Liverpool L69 3BX

A W MACFARLANE, MB, MRCP, registrar in dermatology

\section{Girning as a cause of respiratory obstruction}

Girning is the dialogue form of the present participle of the verb "to girn," which is defined in the Oxford English Dictionary as: "to show teeth in rage, pain, disappointment, etc; to snarl as a dog; to complain persistently; to be fretful or peevish."

In its first meaning girning has come to describe a distortion of the face for the purpose of entertainment or competition to produce the ugliest face. Festivals of girning are held in the north of England each year. The most accomplished exponents of the art of girning tend to be edentulous gentlemen of mature years.

\section{Case report}

Such a patient, aged 64, presented himself for anaesthesia for repair of a recurrent left inguinal hernia (figure: left). This was accomplished without incident. During recovery and after removal of the tracheal tube, however, we observed that total respiratory obstruction was produced by passive protrusion of the mandible by a manoeuvre that is commonly performed to preserve the pharyngeal airway in a comatose patient. In this case it resulted in the upper lip totally occluding the external nares (figure: right). With the mouth closed respiration was impossible. The obstruction occurred only when the patient's dentures were removed.

\section{Comment}

It is now known that the genioglossus muscle contracts rhythmically during the inspiratory phase of respiration in subjects who are awake and

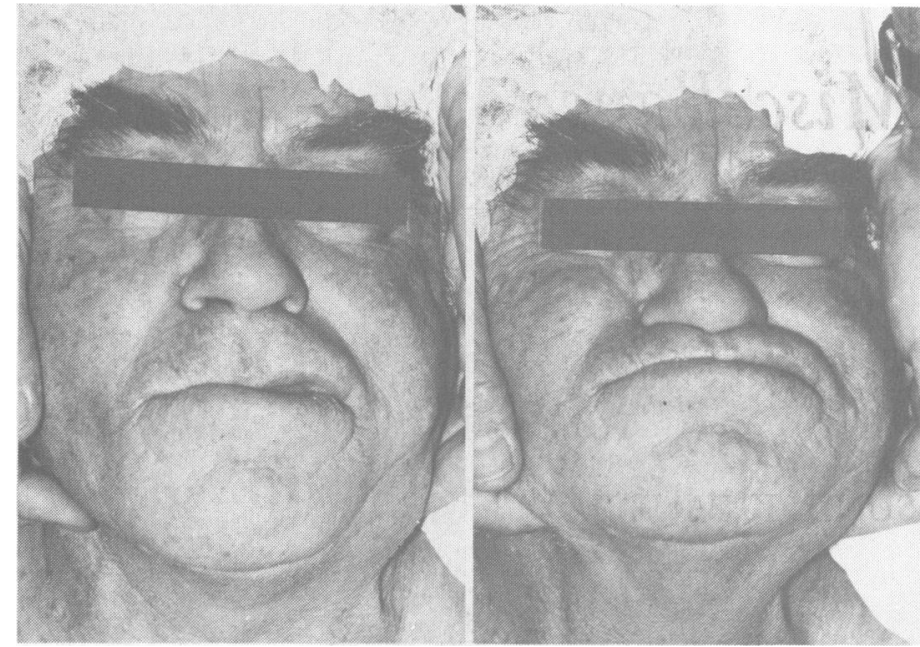

LEFT: Anaesthetised patient with dentures in place and jaw in neutral position. RIGHT: Same patient with dentures removed and jaw protruded in usual manoeuvre to clear pharyngeal airway.

during normal sleep. ${ }^{1}$ This probably holds the posterior third of the tongue away from the posterior pharyngeal wall and so preserves a clear pharyngeal airway.

In cats, however, the onset of anaesthesia.abolishes the phasic contractions of genioglossus. ${ }^{2}$ On the assumption that this also occurs in man, it provides an explanation for the pharyngeal airway obstruction that almost invariably accompanies the onset of anaesthesia, though not normal sleep. It also provides a logical reason for the two manoeuvres that are used to preserve the pharyngeal airway. These are extension of the neck at the altanto-occipital joint and protrusion of the jaw, both of which increase the distance between the genial tubercle and the third cervical vertebra and so tend to lift the tongue away from the posterior pharyngeal wall. It was this second manoeuvre that ironically resulted in total respiratory obstruction in our patient.

We are indebted to Mr A E Kark and to the patient for permission to report this case.

1 Sauerland EK, Harper RM. The human tongue during sleep: electromyographic activity of the genioglossus muscle. Exp Neurol 1976;51:160-70.

2 Nishino $T$, Shirahata $M$, Yonezawa $T$, et al. Comparison of changes in the hypoglossal and the

phrenic nerve activity in response to increasing depth of anesthesia in cats. Anesthesiology 1984;60:19-24.

Department of Anaesthesia, Northwick Park Hospital and Clinical Research Centre, Harrow HAl 3UJ

SUNIL DOGRA, MB, BS, senior house officer

JOHN F NUNN, PHD, FFARCS, consultant

Correspondence to: Dr Nunn.

\section{THE WAY WE LIVE NOW: PARTY REGRETS}

Ever since the end of the war the $B M \mathcal{F}$ has held a large Christmas party for the "Friends of the Journal," not so much for the medical good and the great (those whom the Germans so touchingly call the Prominenten) as for everybody who has helped us in the year-referees, leader writers, advisers, staff, and printers. We send out no fewer than 716 invitations and some 490 actually come to the party, consuming between 6 and $8 \mathrm{pm}$ last week, for instance, 200 bottles of sparkling wine, 150 bottles of Malvern water, 20 whole salmons, 16 turkeys, 1500 sausage rolls, 100 mince pies, and countless other goodies that Mrs Edwina Currie would disapprove of.

For the hosts the party is a high spot of the year, the start of Christmas and enabling us to thank many friends who work for little reward. But until a few years ago the office was snowed under with acceptance letters. Then we introduced the sensible Irish system of "regrets only," and analysis of these might form a basis for a $\mathrm{PhD}$ thesis (written in 2087 by the mythical Philadelphia student, invoked to cow new recruits to the $B M \mathcal{F}$ who question our obsessionalism):

A total of 224 people invited replied with regrets, six by telephone and 14 in their own hand; 21 wrote nice personal letters and the rest replied formally-in a few cases very grandly, with their secretaries pulling out the stop marked Braggadocio ("Professor Gradgrand has asked me to reply to your invitation on his behalf and tender his apologies that ..."). Everybody except me seems to escape the British weather at this time of the year, but only five gave this reason (three raised envious hackles with mentions of India, China, and South America). Two respondents were examining and one consultant was on emergency duty that evening. One serious point was the discovery of how many other important medical events were happening in London that evening - the Rock Carling lecture at the Royal College of Physicians, the Bradshiaw Lecture at the Royal College of Surgeons, and the BLAT film trophy award at Barts, to mention only three. Just as London orchestras have a committee to stop Mahler's 1st symphony being played too often, shouldn't somebody start a medical booking agency to try to stop overlap?

My only regret from this analysis, however, is that of an obsessional grammarian; we oldies have lost the battle between "due to" and "owing to." The former is not a prepositional phrase, but an adjective-yet 25 of our regrets used "due to a prior engagement" compared with only nine who used the correct form. I know that the Cambridge school believes that language is correct whenever over half the population uses a particular word or phrase, but should the $B M \mathcal{F}$ make all of our friends take an English test before deciding whether to invite them next time?-STEPHEN LOCK, Editor, $B M \mathcal{F}$. 